\title{
STUDI ANALISIS Pb(II) MENGGUNAKAN ASAM TANAT EKSTRAK GAMBIR (Uncaria gambir Roxb.) SECARA SPEKTROFOTOMETRI ULTRAUNGU-TAMPAK
}

\author{
Dinda Mezia Physka ${ }^{1}$, R. Supriyanto ${ }^{2}$, dan Ni Luh Ratna Gede Juliasih ${ }^{2}$, Agung Abadi \\ Kiswandono $^{2}$ \\ ${ }^{1}$ Jurusan Kimia FMIPA Universitas Lampung \\ ${ }^{2} J 1$. Prof. Dr. Soemantri Brojonegoro No.1, Bandar Lampung 35145
}

ddindameziaphyska@gmail.com

\section{Artikel Info \\ Diterima tanggal \\ 25.07.2018 \\ Disetujui publikasi tanggal 30.10.2018 \\ Kata kunci : Asam \\ Tanat, Logam \\ $\mathrm{Pb}$ (II), Senyawa \\ Kompleks, \\ Spektrofotometri \\ Ultraungu- \\ Tampak}

\section{ABSTRAK}

Penelitian mempelajari reaksi kordinasi logam $\mathrm{Pb}(\mathrm{II})$ dari senyawa $\mathrm{Pb}\left(\mathrm{NO}_{3}\right)_{2}$ dengan asam tanat ekstrak gambir. Penelitian ini bertujuan untuk mengembangkan metode analisis mengarah kepada kimia hijau dengan memanfaatkan bahan alam dan mendapatkan kondisi optimum dari senyawa kompleks yang terbentuk secara spektrofotometri ultraungu-tampak; serta dapat meperkirakan reaksi yang terbentuk. Metode analisis digunakan untuk mencari $\lambda$ maksimum, $\mathrm{pH}$ optimum, konsentrasi optimum, volume optimum, dan waktu kestabilan optimum. Asam tanat diperoleh $10 \mathrm{mM}$ panjang gelombang maksimum sebesar $275 \mathrm{~nm}$, sedangkan panjang gelombang maksimum logam $\mathrm{Pb}$ (II) diperoleh $277,5 \mathrm{~nm}$. Kondisi optimum pembentukan kompleks $\mathrm{Pb}$-asam tanat ekstrak gambir pada kondisi $\lambda$ maksimum $450 \mathrm{~nm}, \mathrm{pH}$ 9, perbandingan stokiometri konsentrasi (4:1), perbandingan stokiometri volume (2:1), dan waktu kestabilan pada menit ke 30-60 menit. Uji linearitas $\mathrm{Pb}(\mathrm{II})$ diperoleh nilai $\mathrm{R}^{2}$ sebesar 0,9996. Uji presisi memberikan nilai SD dan RSD sebesar 0,012161 dan 1,1488\%. Nilai persen recovery $\mathrm{Pb}$ (II) sebesar 109,998\%. Hasil perhitungan dari limit deteksi memberikan nilai 0,03 dan nilai limit kuantitasi sebesar 0,1 .

\section{ABSTRACT}

This study aims to developed green chemistry method in formation of complex $\mathrm{Pb}$ (II)-tannic acid of gambier extract; optimum conditions complex formation was conducted by using spectrophotometry ultraviolet-visible. The maximum wavelength, optimum $\mathrm{pH}$, optimum concentration, optimum volume, and optimum time-stability was determined. The maximum wavelength of tannic acid obtained at 275 $\mathrm{nm}$, whereas the optimum wavelength of $\mathrm{Pb}$ (II) achieved $277,5 \mathrm{~nm}$. The result showed that the optimum condition of complex $\mathrm{Pb}$ (II)-tannic acid was obtained at $450 \mathrm{~nm}, \mathrm{pH} 9$, with the ratio of stoichiometry concentracion was (4:1), with the ratio stoichiometry volume was $(2: 1)$, and stability time after 30-60 minutes. The linearity test toward $\mathrm{Pb}$ (II) was achieved with the correlation coefficient $\left(\mathrm{R}^{2}\right)$ of 0,9996 . The precision was conducted in SD and RSD test, it is 0,012161 and $1,1488 \%$ respectively for $\mathrm{Pb}(\mathrm{II})$. The recovery value of $\mathrm{Pb}(\mathrm{II})$ was $109,998 \%$. The LoD and LoQ for this method was 0,03 and 0,1 .

\section{PENDAHULUAN}

Dewasa ini, dunia industri di Indonesia berkembang pesat. Seiring perkembangan tersebut dapat memberikan dampak negatif,yaitu meningkatnya konsentrasi bahan-bahan pencemar,salah satunya logam 
berat. Hal ini disebabkan karena logam berat bersifat toksik dan karsiogenik meskipun pada konsentrasi yang rendah dan umumnya bersifat akumulatif sebagai polutan bagi lingkungan (Saputra, 2016). Salah satu logam berat yang sangat berbahaya dan mencemari lingkungan ialah timbal $(\mathrm{Pb})$.

Metode yang sering dilakukan untuk menganalisis logam timbal $(\mathrm{Pb})$ ialah spektrofotometri serapan atom (Kumalawati, 2016). Spektrofotometri serapan atom sangat spesifik untuk mengetahui kadar timbal $(\mathrm{Pb})$ dalam suatu sampel. Metode lain untuk analisis logam timbal $(\mathrm{Pb})$ adalah spektrofotometri ultraungu-tampak dengan cara pembentukan kompleks $\mathrm{Pb}$ (II) dengan ligan tertentu. Analisis spektrofotometri ultraungu-tampak pada pembetukan kompleks $\mathrm{Pb}$ (II) dengan ligan asam tartarat pada panjang gelombang $430 \mathrm{~nm}$ dan absorbansi diperoleh sebesar 0,449 (Fajriati dan Endah, 2010). Kompleks antara asam tanat dengan $\mathrm{CaCO}_{3}$ memperoleh panjang gelombang $320 \mathrm{~nm}$ (Zhang dkk, 2017).

Penelitian ini dilakukan untuk mendapatkan kondisi optimum pembentukan senyawa kompleks antara ekstrak gambir yang mengandung asam tanat dengan $\mathrm{Pb}(\mathrm{II})$ berbagai macam variasi konsentrasi dan volume yang dipelajari dengan metode spektrofotometri ultraungu-tampak. Penelitian ini diharapkan dapat digunakan sebagai metode alternatif baru dalam analisis logam $\mathrm{Pb}$ (II) yangefektif, efisien, mudah, dan murah penggunaannya.

\section{METODE}

\section{Alat dan Bahan}

Alat-alat yang digunakan dalam penelitian ini antara lain neraca analitik,pH meter, spektrofotometer ultraungu-tampak, mikro pipet, pipet tetes, labu ukur, gelas ukur, beaker glass, oven, dan kuvet. Bahan yang digunakan dalam percobaan ini terdiri dari ekstrak gambir yang mengandung asam tanat, alumunium foil, etanol, akubides, akuades, $\mathrm{Pb}\left(\mathrm{NO}_{3}\right)_{2}, \mathrm{NaOH}$, dan tisu kering.

\section{Prosedur}

\section{Preparasi Larutan Induk}

\section{a. Pembuatan Larutan Ekstrak Gambir yang Mengandung Asam Tanat 10 mM.}

Larutan induk ekstrak gambir yang mengandung asam tanat $10 \mathrm{mM}$ dibuat dengan cara menimbang 1,7012 g bubuk ekstrak gambir yang mengandung asam tanat, kemudian dimasukan ke dalam labu takar $100 \mathrm{~mL}$ lalu ditambahkan akuabides hingga tanda batas dan dihomogenkan. 


\section{b. Pembuatan Larutan Pb(II) $10 \mathrm{mM}$.}

Larutan induk $\mathrm{Pb}(\mathrm{II})$ dibuat dengan cara menimbang bubuk $\mathrm{Pb}\left(\mathrm{NO}_{3}\right)_{2}$ sebanyak $0,3312 \mathrm{~g}$, dimasukan ke dalam labu takar $100 \mathrm{~mL}$ lalu ditambahkan akuabides hingga tanda batas dan dihomogenkan.

\section{c. Pembuatan Larutan NaOH 0,1 M}

Membuat larutan $\mathrm{NaOH}$ 0,1 $\mathrm{M}$ dengan cara menimbang $4 \mathrm{~g} \mathrm{NaOH}$ yang dilarutkan dalam labu takar $100 \mathrm{~mL}$ lalu ditambahkan akuades hingga tanda batas dan dihomogenkan.

\section{Penentuan Panjang Gelombang Maksimum}

a. Penentuan Panjang Gelombang Maksimum Larutan Ekstrak Gambir yang Mengandung Asam Tanat.

Memasukan sebanyak $4 \mathrm{~mL}$ larutan ekstrak gambir yang mengandung asam tanat kedalam kuvet, kemudian mengukur panjang gelombang menggunakan spektrofotometer ultraungu-tampak.

\section{b. Penentuan Panjang Gelombang Maksimum Larutan Pb(II).}

Memasukan sebanyak 4 mL larutan $\mathrm{Pb}$ (II) kedalam kuvet, kemudian mengukur panjang gelombang menggunakan spektrofotometer ultraungu-tampak.

c. Penentuan Panjang Gelombang Maksimum Reaksi Larutan Ekstrak Gambir yang Mengandung Asam Tanat-Pb(II).

Penentuan panjang gelombang maksimum reaksi ekstrak gambir yang mengandung asam tanat dan $\mathrm{Pb}$ (II) dilakukan dengan menambahkan masing-masing $2 \mathrm{~mL}$ larutan $\mathrm{Pb}$ (II) 0,01 mM dan ekstrak gambir yang mengandung asam tanat $1 \mathrm{mM}$, dimasukan kedalam kuvet, kemudian diukur menggunakan spektrofotometer ultraungu-tampak.

\section{Penentuan Variasi pH OptimumKompleks Ekstrak Gambir yang Mengandung Asam} Tanat-Pb(II)

Penentuan variasi $\mathrm{pH}$ dilakukan dengan cara mereaksikan $\mathrm{Pb}(\mathrm{II})$-ekstrak gambir yang mengandung asam tanat dengan skala kenaikan pH 7; 8; 9; 10; dan 11. Setelah itu dilakukan optimasi pada panjang gelombang maksimum menggunakan spektrofotometer ultraungu-tampak. 


\section{Penentuan Stokiometri Kompleks Ekstrak Gambir yang Mengandung Asam Tanat- $\mathrm{Pb}(\mathrm{II})$ \\ a. Penentuan Stokiometri Kompleks Ekstrak Gambir yang Mengandung Asam Tanat-Pb(II) dengan Variasi Konsentrasi Pb(II) (mM)}

Pengukuran ekstrak gambir yang mengandung asam tanat- $\mathrm{Pb}$ (II) dilakukan pada $\mathrm{pH}$ optimum dan panjang gelombang maksimum dengan perbandingan konsentrasi $\mathrm{Pb}(\mathrm{II})$-ekstrak gambir yang mengandung asam tanat 1:1, 1:2, 1:3,1:4, dan 1:5. Absorbansi diukur menggunakan spektrofotometer ultraungu-tampak.

\section{b. Penentuan Stokiometri Kompleks Ekstrak Gambir yang Mengandung Asam Tanat-Pb(II)} dengan Variasi Konsentrasi Ekstrak Gambir yang Mengandung Asam Tanat (mM) Pengukuran ekstrak gambir yang mengandung asam tanat- $\mathrm{Pb}$ (II) dilakukan pada $\mathrm{pH}$ optimum dan panjang gelombang maksimum dengan perbandingan konsentrasi $\mathrm{Pb}$ (II)-ekstrak gambir yang mengandung asam tanat 1:1, 2:1, 3:1, 4:1, dan 5:1. Absorbansi diukur menggunakan spektrofotometer ultraungu-tampak.

c. Penentuan Stokiometri Kompleks Ekstrak Gambir yang Mengandung Asam Tanat-Pb(II) dengan Variasi Volume $\mathrm{Pb}(\mathrm{II})(\mathrm{mL})$

Pengukuran ekstrak gambir yang mengandung asam tanat- $\mathrm{Pb}$ (II) dilakukan menggunakan $\mathrm{pH}$ optimum, perbandingan konsentrasi optimum, pada panjang gelombang maksimum dengan memvariasikan volume dengan perbandingan 1:1, 1:2, 1:3, 1:4, dan 1:5. Absorbansi diukur menggunakan spektrofotometer ultraungu-tampak.

\section{d. Penentuan Stokiometri Kompleks Ekstrak gambir yang Mengandung Asam Tanat-Pb(II) dengan Variasi Volume Ekstrak Gambir yang Mengandung Asam Tanat (mL)} Pengukuran ekstrak gambir yang mengandung asam tanat- $\mathrm{Pb}$ (II) dilakukan pada $\mathrm{pH}$ optimum, perbandingan konsentrasi optimum, pada panjang gelombang maksimum dengan memvariasikan volume dengan perbandingan 1:1, 2:1, 3:1, 4:1, dan 5:1. Absorbansi diukur menggunakan spektrofotometer ultraungu-tampak.

\section{Penentuan Waktu Kestabilan Ekstrak Gambir yang Mengandung Asam Tanat-Pb(II)} Penentuan waktu kestabilan dilakukan dengan memilih pH optimum, perbandingan konsentrasi optimum, dan volume optimum, kemudian diukur absorbansinya dengan menggunakan spektrofotometer ultraungu-tampak pada panjang gelombang maksimum dari 0 menit sampai 60 menit dengan skala kenaikan 10 menit. 


\section{Validasi Metode}

\section{Penentuan Liniearitas Kurva Kalibrasi $\mathbf{P b}$ (II)}

Uji linearitas dilakukan dengan membuat larutan $\mathrm{Pb}(\mathrm{II})$ dengan konsentrasi berbeda yaitu 1, 3, 5, 7, $9 \mathrm{mM}$ yang diencerkan dari larutan standar $10 \mathrm{mM}$, diukur absorbansi dengan menggunakan spektrofotometer ultraungu-tampak. Nilai absorbansi yang diperoleh dicatat kemudian diproses dengan metode kuadrat terkecil untuk menentukan nilai kemiringan (slope), intersep, dan koefisien korelasi. Setelah itu dibuat persamaan linear antara konsentrasi dengan absorbansi. Nilai r yang diperoleh menggambarkan linearitas.

\section{Penentuan Akurasi}

Uji akurasi dilakukan dengan menambahkan sejumlah analit murni kedalam campuran.

Kemudian campuran di analisis dan hasilnya dibandingkan terhadap kadar analit yang ditambahkan (kadar sebenarnya). Jumlah analit yang ditambahkan ke dalam sampel atau selisih antara rata-rata dan nilai sebenarnya yang dapat ditunjukkan ketepatannya. Ketepatan dihitung sebagai persen recovery (perolehan kembali).

\section{Penentuan Presisi}

Uji presisi ini dilakukan dengan cara mengukur konsentrasi sampel dengan melakukan 6 kali pengulangan. Nilai absorbansi yang diperoleh dapat ditentukan simpangan baku (SD) dan nilai relatif standar deviasi (RSD). Metode dengan presisi yang baik ditunjukkan dengan perolehan relatif standar deviasi $(\mathrm{RSD})<5 \%$.

\section{Penentuan Limit Dereksi (LoD) dan Limit Kuantifikasi (LoQ)}

Penentuan LoD dan LoQ untuk logam $\mathrm{Pb}$ diperoleh dari pengukuran sampel dengan konsentrasi terendah namun masih memberikan respon yang signifikan, kemudian hasil pengukuran dihitung berdasarkan persamaan kurva kalibrasi yang diperoleh. 


\section{HASIL DAN PEMBAHASAN}

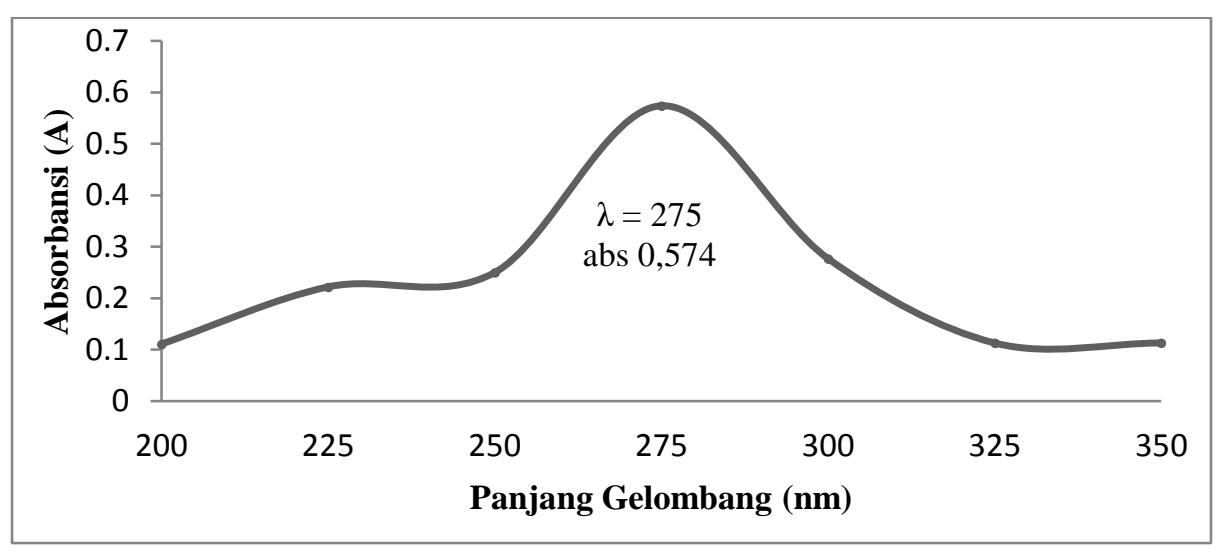

Gambar 1. Kurva Panjang Gelombang Maksimum Ekstrak Gambir yang Mengandung Asam Tanat Terhadap Absorbansi

Panjang gelombang maksimum larutan ekstrak gambir yang mengandung asam tanat $10 \mathrm{mM}$ diperoleh pada $275 \mathrm{~nm}$ dengan absorbansi sebesar 0,574 .

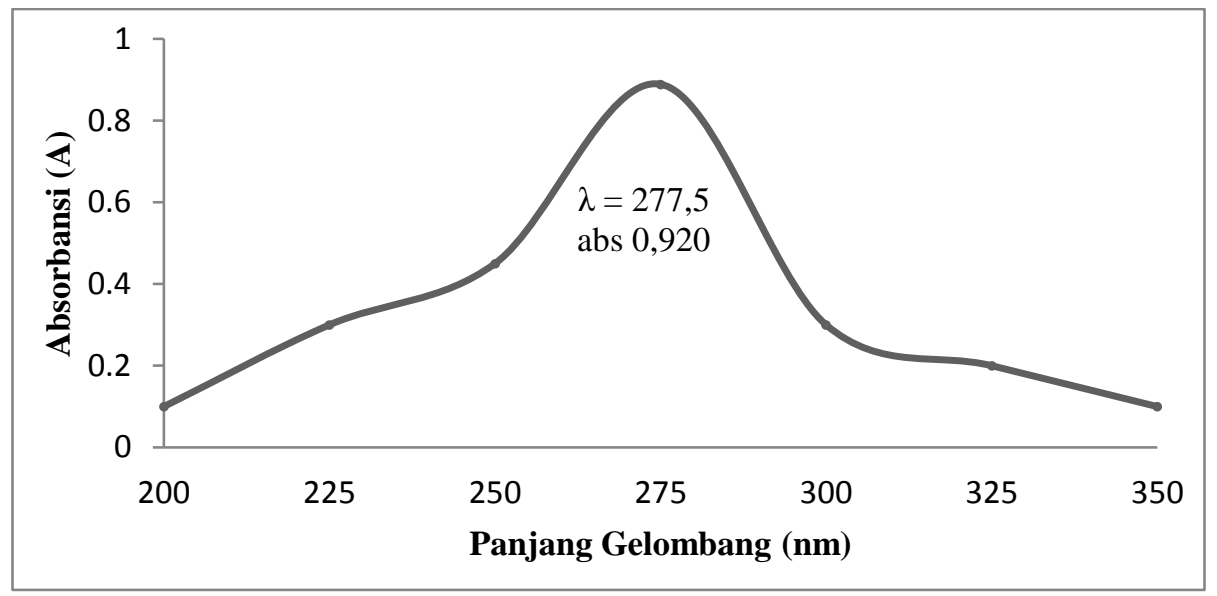

Gambar 2. Kurva Panjang Gelombang Maksimum Pb(II) Terhadap Absorbansi

Penentuan panjang gelombang maksimum $\mathrm{Pb}(\mathrm{II}) 10 \mathrm{mM}$ dilakukan dengan cara mengukur panjang gelombang pada rentang 200-400 nm.Gambar larutan $\mathrm{Pb}$ (II) dapat dilihat pada Lampiran 2B.Panjang gelombang maksimum $\mathrm{Pb}$ (II) $10 \mathrm{mM}$ diperoleh pada 277,5 $\mathrm{nm}$ dengan absorbansi sebesar 0,920 . 


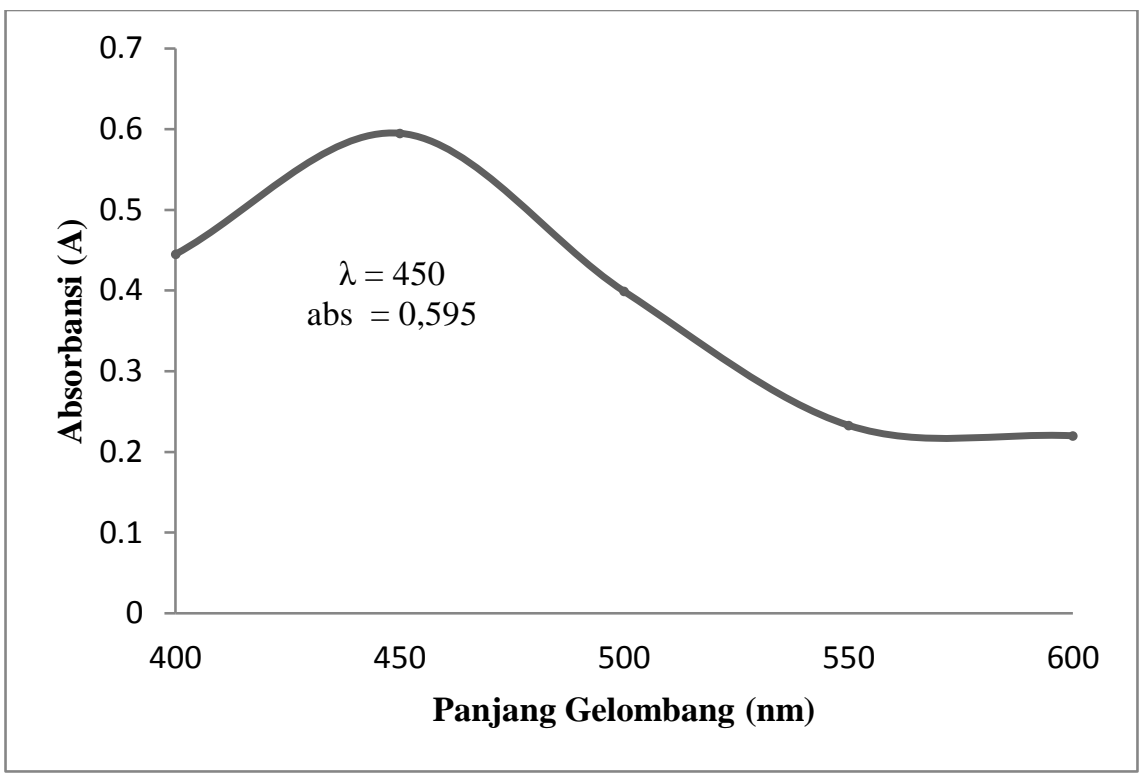

Gambar 3. Panjang Gelombang Reaksi Ekstrak Gambir yang Mengandung Asam Tanat-Pb(II) Terhadap Absorbansi

Panjang gelombang maksimum kompleks ekstrak gambir yang mengandung asam tanat $\mathrm{Pb}(\mathrm{II})$ diperoleh pada $450 \mathrm{~nm}$ dengan absorbansi sebesar 0,595. Reaksi ekstrak gambir yang mengandung asam tanat- $\mathrm{Pb}(\mathrm{II})$ ditunjukkan dengan adanya pergeseran panjang gelombang kearah yang lebih besar atau disebut juga efek batokromik (pergeseran merah).

Tabel 1. Pengaruh Variasi pH Terhadap Absorbansi Kompleks Ekstrak Gambir yang Mengandung Asam Tanat-Pb(II)

\begin{tabular}{ccc}
\hline $\mathrm{pH}$ & Absorbansi & Panjang Gelombang \\
\hline 7 & 0,330 & 450 \\
8 & 0,436 & 450 \\
9 & 0,595 & 450 \\
10 & 0,317 & 450 \\
11 & 0,089 & 450 \\
\hline
\end{tabular}

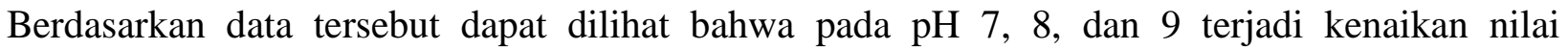
absorbansi, sedangkan pada pH 10 dan 11 mengalami penurunan nilai absorbansi. Hal ini berarti $\mathrm{pH}$ optimum untuk kompleks ekstrak gambir yang mengandung asam tanat- $\mathrm{Pb}$ (II) yaitu pada pH 9 dengan nilai absorbansi sebesar 0,595. Menurut (Supriyanto, 2011) ekstrak gambir yang mengandung asam tanat dapat bereaksi membentuk senyawa kompleks apabila $\mathrm{pH}$ diatas 8 . 
Tabel 2. Pengaruh Variasi Konsentrasi Terhadap Nilai Absorbansi Kompleks Ekstrak Gambir yang Mengandung Asam Tanat-Pb(II)

\begin{tabular}{cccc}
\hline $\begin{array}{c}\text { Ekstrak gambir yang mengan- } \\
\text { dung asam tanat : } \mathrm{Pb}(\mathrm{II})\end{array}$ & Absorbansi & $\mathrm{pH}$ & $\begin{array}{c}\text { Panjang } \\
\text { Gelombang }\end{array}$ \\
\hline $1: 1$ & 0,446 & 9 & 450 \\
$1: 2$ & 0,527 & 9 & 450 \\
$1: 3$ & 0,511 & 9 & 450 \\
$1: 4$ & 0,496 & 9 & 450 \\
$1: 5$ & 0,480 & 9 & 450 \\
$2: 1$ & 0,390 & 9 & 450 \\
$3: 1$ & 0,377 & 9 & 450 \\
$4: 1$ & 0,625 & 9 & 450 \\
$5: 1$ & 0,540 & 9 & 450 \\
\hline
\end{tabular}

Berdasarkan data yang didapat, absorbansi optimum ditunjukkan pada perbandingan konsentrasi antara ekstrak gambir yang mengandung asam tanat dan $\mathrm{Pb}(\mathrm{II})$ 4:1.

Tabel 3. Pengaruh Variasi Volume Terhadap Absorbansi Kompleks Ekstrak Gambir yang Mengandung Asam Tanat-Pb(II)

\begin{tabular}{ccccc}
\hline $\begin{array}{c}\text { Ekstrak gambir yang mengan- } \\
\text { dung asam tanat }: \mathrm{Pb}(\mathrm{II})\end{array}$ & Absorbansi & $\mathrm{pH}$ & Konsentrasi & $\begin{array}{c}\text { Panjang } \\
\text { Gelombang }\end{array}$ \\
\hline $1: 1$ & 0,520 & 9 & $4: 1$ & 450 \\
$1: 2$ & 0,522 & 9 & $4: 1$ & 450 \\
$1: 3$ & 0,530 & 9 & $4: 1$ & 450 \\
$1: 4$ & 0,543 & 9 & $4: 1$ & 450 \\
$1: 5$ & 0,494 & 9 & $4: 1$ & 450 \\
$2: 1$ & 0,838 & 9 & $4: 1$ & 450 \\
$3: 1$ & 0,690 & 9 & $4: 1$ & 450 \\
$4: 1$ & 0,685 & 9 & $4: 1$ & 450 \\
$5: 1$ & 0,500 & 9 & $4: 1$ & 450 \\
\hline
\end{tabular}

Berdasarkan data yang didapat absorbansi optimum ditunjukkan pada perbandingan volume antara ekstrak gambir yang mengandung asam tanat dan $\mathrm{Pb}(\mathrm{II})$ yakni (2:1). Hal ini dapat dikatakan bahwa variasi volume (2:1) menunjukkan komposisi tepat untuk membentuk senyawa kompleks ekstrak gambir yang mengandung asam tanat- $\mathrm{Pb}(\mathrm{II})$. 
Tabel 4. Penentuan Waktu Kestabilan Kompleks Ekstrak Gambir yang Mengandung Asam Tanat-Pb(II)

\begin{tabular}{cccccc}
\hline $\begin{array}{l}\text { Waktu } \\
\text { (Menit) }\end{array}$ & Absorbansi & $\begin{array}{c}\text { Panjang } \\
\text { Gelombang }\end{array}$ & $\mathrm{pH}$ & Konsentrasi & Volume \\
\hline 0 & 0,267 & 450 & 9 & $4: 1$ & $2: 1$ \\
10 & 0,529 & 450 & 9 & $4: 1$ & $2: 1$ \\
20 & 0,715 & 450 & 9 & $4: 1$ & $2: 1$ \\
30 & 0,893 & 450 & 9 & $4: 1$ & $2: 1$ \\
40 & 0,893 & 450 & 9 & $4: 1$ & $2: 1$ \\
50 & 0,893 & 450 & 9 & $4: 1$ & $2: 1$ \\
60 & 0,893 & 450 & 9 & $4: 1$ & $2: 1$ \\
\hline
\end{tabular}

Berdasarkan data di Tabel 8 maka kompleks ekstrak gambir yang mengandung asam tanat-Pb(II) stabil setelah menit ke-30 dengan absorbansi sebesar 0,893.

\section{Linearitas}

Tabel 5. Tabel Nilai Uji Linearitas Larutan $\mathrm{Pb}(\mathrm{II})$

\begin{tabular}{lcc}
\hline No & Konsentrasi $(\mathrm{mM})$ & Absorbansi \\
\hline 1. & 0 & 0 \\
2. & 1 & 0,109 \\
3. & 3 & 0,289 \\
4. & 5 & 0,463 \\
5. & 7 & 0,645 \\
6. & 9 & 0,828 \\
& Stok $\mathrm{Pb}(\mathrm{II}) 10 \mathrm{mM}$ & 0,920 \\
\hline
\end{tabular}

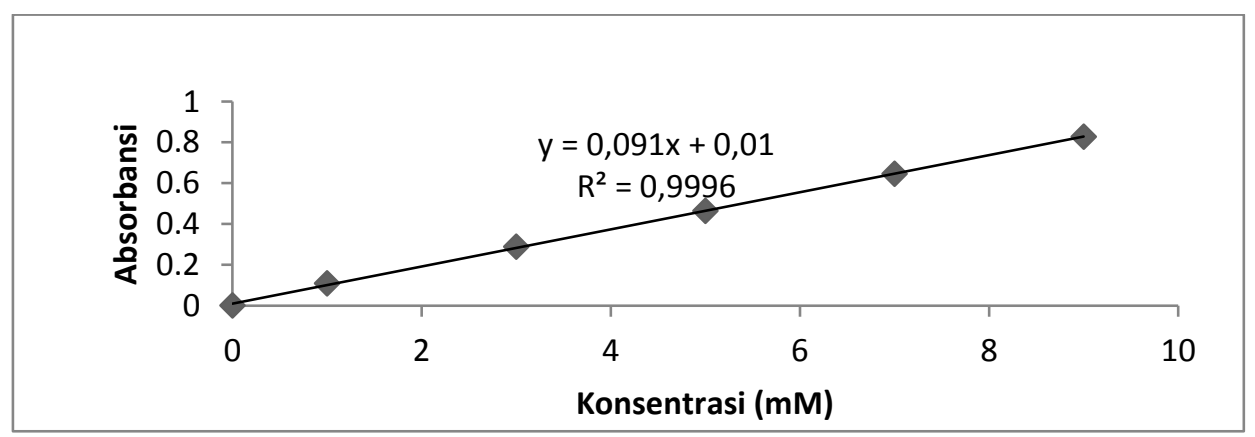

Gambar 4. Kurva Kalibrasi Larutan Pb(II) Terhadap Absorbansi

Kurva kalibrasi larutan $\mathrm{Pb}(\mathrm{II})$ adalah $\mathrm{y}=0,091 \mathrm{x}+0,01$ dan koefisien korelasinya sebesar 0,9996. Nilai koefisien korelasi yang mendekati 1 dapat dikatakan baik, sehingga metode analisis uji kompleks ekstrak gambir yang mengandung asam tanat- $\mathrm{Pb}(\mathrm{II})$ memenuhi persyaratan. 


\section{Ketepatan (Akurasi)}

Berdasarkan perhitungan persen recovery analisis $\mathrm{Pb}$ dengan pembentukan kompleks ekstrak gambir yang mengandung asam tanat- $\mathrm{Pb}(\mathrm{II})$ pada penelitian ini diperoleh sebesar 109,998 \% .

\section{Ketelitian (Presisi)}

Tabel 6. Nilai Asorbansi Uji Ketelitian

\begin{tabular}{cc}
\hline Pengulangan & Absorbansi \\
\hline 1 & 0,105 \\
2 & 0,107 \\
3 & 0,107 \\
4 & 0,106 \\
5 & 0,105 \\
6 & 0,108 \\
\hline SD 0,012161 & \\
RSD $1,1488 \%$ & \\
\hline
\end{tabular}

Nilai SD dan RSD yang didapat masing-masing sebesar 0,012161 dan 1,1488 \%. Hasil perhitungan yang diperoleh pada penelitian ini tergolong baik untuk penggunaan metode sebagai uji analisis logam $\mathrm{Pb}(\mathrm{II})$.

\section{Limit Deteksi dan Limit Kuantitasi}

Nilai limit deteksi hasil penelitian menunjukkan bahwa metode yang digunakan dalam penelitian ini mampu memberikan respon untuk analisis logam dengan jumlah analit yang kecil. Nilai limit kuantitasi yang dapat menunjukkan bahwa metode dalam penelitian ini mampu memberikan respon dengan nilai akurasi dan presisi yang dapat diterima dalam analisis. Hasil perhitungan limit deteksi dan limit kuantitasi pada kompleks ekstrak gambir yang mengandung asam tanat$\mathrm{Pb}$ (II) berturut-turut sebesar 0,03 dan 0,1 .

\section{KESIMPULAN}

Panjang gelombang maksimum ekstrak gambir yang mengandung asam tanat- $\mathrm{Pb}$ (II) diperoleh pada sinar tampak sebesar $450 \mathrm{~nm}$ dengan konsentrasi $\mathrm{Pb}$ (II) 0,01 mM dan ekstrak gambir yang mengandung asam tanat $1 \mathrm{mM}$, dimana terbentuk kompleks berwarna kuning kecoklatan. Kondisi Optimum kompleks ekstrak gambir yang mengandung asam tanat- $\mathrm{Pb}(\mathrm{II}) \mathrm{pH}$ 9, perbandingan stokiometri konsentrasi 4:1 (ekstrak gambir yang mengandung asam tanat : 
$\mathrm{Pb}(\mathrm{II})$ ), perbandingan stokiometri volume 2:1 (ekstrak gambir yang mengandung asam tanat : $\mathrm{Pb}(\mathrm{II})$ ), dengan waktu kestabilan kompleks pada waktu30-60 menit. Uji linearitas metode diperolehnilai r sebesar 0,9996. Pada uji SD dan RSD diperoleh nilai sebesar0,001053 dan 0,9\%. Nilai persen recovery metode sebesar 109,998 \%. Nilai limit deteksi dan limit kuantitasi berturut-turut sebesar 0,03 dan 0,1 .

\section{DAFTAR PUSTAKA}

Almunjiat, E., Yusuf,S., dan Ainurafiq. 2016. Analisis Resiko Kesehatan Akibat Pajanan Timbal (Pb) Melalui Jalur Inhalasi Pada Operator Di Stasiun Pengisian Bahan Bakar Umum (SPBU) Di Kota Kendari. Jurnal Akademik Kimia Universitas Halu Oleo. Kendari.

Fajriati, I. dan Endah,E.A. 2010. Penetapan Logam Timbal Secara Spektrofotometri Sinar Tampak. Makalah Pendamping: Kimia. 72-76.

Kumalawati, R.O. 2016. Analisis Kadar Logam Timbal (Pb) Pada Bedak Tabur Dengan Variasi Zat Pengoksidasi dan Metode Dekstruksi Basah Menggunakan Spektrofotometer Serapan Atom (Skripsi). Universitas Islam Negeri Maulana Malik Ibrahim. Malang.

Palar, Heryando. 1994. Pencemaran dan Toksikologi Logam Berat. PT. Rineka Cipta. Jakarta.

Saputra, M.B. 2016. Pengaruh $\mathrm{HNO}_{3}$ dan NaOH Pada Analisis Cr(III) Menggunakan Asam Tanat Secara Spektrofotometri Ultraungu-Tampak (Skripsi). Universitas Lampung. Lampung.

Supriyanto, R. 2010. Studi Analisis Ion Logam Cr(III) dan Cr(IV) dengan Asam Tanat dari Ekstrak Gambir Secara Spektrofotometri UV-Vis. Jurnal Sains MIPA. 35-42.

Widowati,W.,Sastiono,A.,dan Jusuf,R. 2008. Efek Toksik Logam Pencegahan dan Penanggulangan Pencemaran. CV. Andi Offset. Yogyakarta.

Zhang, C., Wei, S., dan Hu, C. 2017. Selective Adsorption of Tannic Acid on Calcite and Implications for Separation of Flourite Minerals. Journal of Colloid and Interface Science. School of Mineral Processing and Bioengineering, Central South University. China. 